
\title{
Research S Surate \\ Influence of Native Ureolytic Microbial Community on Biocementation Potential of Sporosarcina Pasteurii
}

\section{Raja Murugan}

Indian Institute of Technology Madras

G. K. Suraishkumar

Indian Institute of Technology Madras

Abhijit Muhkerjee

Curtin University

Navdeep K Dhami ( $\square$ navdeep.dhami@curtin.edu.au )

Curtin University

\section{Research Article}

Keywords: Native Ureolytic Microbial Community, Biocementation Potential, Sporosarcina Pasteurii

Posted Date: July 9th, 2021

DOI: https://doi.org/10.21203/rs.3.rs-687770/v1

License: (c) (i) This work is licensed under a Creative Commons Attribution 4.0 International License. Read Full License 


\section{Influence of Native Ureolytic Microbial Community on}

2

5 Chennai - 600036, India.

$6{ }^{2}$ School of Civil and Mechanical Engineering, Curtin University, Western Australia - 6102,

7 Australia.

8 Correspondence and requests for material should be addressed to N.K.D. (email:

9 navdeep.dhami@curtin.edu.au)

\section{ABSTRACT}

11 Microbially induced calcium carbonate precipitation (MICP)/Biocementation has emerged as

12 a promising technique for soil engineering applications. There are chiefly two methods by which MICP is applied for field applications including biostimulation and bioaugmentation. Although bioaugmentation strategy using efficient ureolytic biocementing culture of Sporosarcina pasteurii is widely practiced, the impact of native ureolytic microbial communities (NUMC) on $\mathrm{CaCO}_{3}$ mineralisation via $S$. pasteurii has not been explored. In this paper, we investigated the effect of different concentrations of NUMC on MICP kinetics and biomineral properties in the presence and absence of $S$. pasteurii. Kinetic analysis showed that the biocementation potential of $S$. pasteurii is 6-fold higher than the NUMC and is not significantly impacted even when the concentration of the NUMC is eight times higher. Micrographic results revealed a quick rate of $\mathrm{CaCO}_{3}$ precipitation by $S$. pasteurii led to the generation of smaller $\mathrm{CaCO}_{3}$ crystals $(5-40 \mu \mathrm{m})$, while the slow rate of $\mathrm{CaCO}_{3}$ precipitation by NUMC led to the creation of larger $\mathrm{CaCO}_{3}$ crystals $(35-100 \mu \mathrm{m})$. Mineralogical results 
24 showed the predominance of the calcite phase in both sets. The outcome of the current study is crucial for tailor-made applications of MICP.

\section{INTRODUCTION}

27 Microbially induced calcium carbonate precipitation (MICP) is a ubiquitously recorded process in nature and is responsible for the creation of numerous geological formations in terrestrial and marine environments ${ }^{1}$. Recently this process has been replicated in the lab conditions for numerous engineering applications, as it leads to the formation of carbonate cement at ambient temperature conditions by harnessing the cementation potential of living microorganisms. The major applications include improvement of mechanical properties of $\operatorname{soil}^{2,3}$, bioremediation of heavy metals and radio nucleotides ${ }^{4-6}$, enhancement of oil recovery ${ }^{7}$, repair of concrete cracks ${ }^{8,9}$, and sequestration of atmospheric $\mathrm{CO}_{2}{ }^{10}$. The chief benefit of this bio-mimicked cementation process includes self-healing ability, eco-friendliness, recyclability, and low viscosity paving the way for deeper penetration ${ }^{11}$.

MICP/Biocementation occurs via various metabolic pathways of bacteria such as ureolysis, denitrification, sulfate reduction, and iron reduction ${ }^{12}$. Amongst the different pathways, MICP via ureolytic pathway is the most widely explored route because of its straightforwardness, efficacy, short time, and no excess production of protons ${ }^{13,14}$. In the microbial ureolytic pathway, urea is hydrolysed into ammonia and carbon dioxide by the action of urease ${ }^{2}$. Subsequently, these products equilibrate in water to form bicarbonate, ammonium, and hydroxide ions, which elevate the $\mathrm{pH}$ of the microenvironment around the bacteria (equation 1). An increase in $\mathrm{pH}$ favors the equilibrium shifts from bicarbonate ions to carbonate ions. The formed carbonate ions then precipitate as calcium carbonate on the bacterial surface in the presence of calcium ${ }^{2}$ (equation 2). 
For applications of MICP in soils, especially in the field, there are two modes by which calcifying bacteria are supplemented: biostimulation (enrichment of native population) or bioaugmentation (supplementation of efficient foreign bacteria). The biostimulation approach deals with the modification of existing field conditions by altering the nutrients, substrates, and electron acceptors to enrich the native microorganisms for accelerating the $\mathrm{CaCO}_{3}$ precipitation; whereas, bioaugmentation includes the addition of highly potential ureolytic and cementing strains especially Sporosarcina pasteurii into the fields ${ }^{32-36}$. Comparing these two approaches, MICP through bioaugmentation has a major advantage as it is a rapid process. This benefit makes this approach quite attractive for engineering applications, despite having the limitation of cost factor for preparation and transport of bacterial cultures ${ }^{35}$. On the other hand, biostimulation utilizes native bacteria making the MICP process both economically and environmentally viable ${ }^{35}$. Furthermore, the stimulation approach may eliminate the possible ecological impacts caused by a non-indigenous bacterial introduction in the applied soil environment, but the process rate is generally slow in comparison to the bioaugmentation approach $^{37}$. The studies conducted on utilisation of both the approaches for improving the soil engineering properties reported that changes in solution chemistry and distribution of $\mathrm{CaCO}_{3}$ precipitate occurred invariably in 1-meter soil column during biostimulation ${ }^{37}$; however, bioaugmentation with $S$. pasteurii led to significant improvement in strength, stiffness, loadbearing capacity and hydraulic conductivity of the soil ${ }^{12,37,38}$. Although researchers have demonstrated biogeochemical changes during the biostimulation approach, not much has been investigated on the impact of native ureolytic microbial communities (NUMC) on the performance of $S$. pasteurii and how these communities perform in comparison to this high urease producing culture ${ }^{37}$. Also, the concentration of NUMC changes vastly in the field and may affect the kinetics of the $\mathrm{CaCO}_{3}$ process, its mineralogy, and morphology which are the determining factors for the success of biocementation ${ }^{22}$. 
74 Kinetic aspects of the $\mathrm{CaCO}_{3}$ precipitation decide the overall efficacy of biocementation and are influenced by both abiotic and biotic factors including temperature, $\mathrm{pH}$, aeration, nutrient availability, bacterial concentration, and type of bacteria or type of microbial population ${ }^{15-21}$. Amongst all these factors, the concentration of bacteria and urease enzyme is a crucial factor ${ }^{22}$ and is reflected in the kinetic constant of the $\mathrm{CaCO}_{3}$ precipitation in terms of first-order rate constant of 0.002 to $0.60 \mathrm{~h}^{-1} 23-25$. Further, the kinetics of the process also control the morphological and nanomechanical properties of the precipitated $\mathrm{CaCO}_{3}$; the slow rate of precipitation leads to the production of larger-sized crystals that are relatively stable compared to the smaller crystals formed at a high rate of precipitation ${ }^{26,27}$.

In general, microbially induced $\mathrm{CaCO}_{3}$ precipitate is a cohesive material ${ }^{2}$ and exists in different crystalline phases including calcite, vaterite, aragonite, monohydrocalcite, and ikaite ${ }^{1}$. The sizes of these crystals vary from $5-100 \mu \mathrm{m}$ along with variations in their nanomaterial properties ${ }^{28-30}$. Essential properties such as size, shape, stability, solubility, and hardness of the $\mathrm{CaCO}_{3}$ crystals determine the efficacy of MICP in engineering applications. For example, the conservation of building materials required more stable calcite than metastable vaterite and larger rhombohedral crystals $(100-150 \mu \mathrm{m})$ are more preferable in soil stabilization applications ${ }^{31}$. But very little information is available on these aspects including the impact of native communities on MICP kinetics with and without S. pasteurii, the effect of the concentration of native communities on MICP, and the influence of kinetic factors on morphomineralogical properties of carbonate crystals. All these factors are crucial in determining the efficacy of biocementation for field applications. The purpose of this study is to 1) evaluate the influence of native ureolytic microbial community (NUMC) at varying concentrations on biocementation kinetics 2) analyse the bioaugmentation potential of $S$. pasteurii in presence of different concentrations of native ureolytic microbial community and 
3) investigate the effect of different cell concentrations of NUMC on morphologicalmineralogical properties of S. pasteurii driven MICP.

100 We hypothesize that the outcome of this study will help to tailor MICP kinetics, morphology, 101 mineralogy, and material properties of biomineralised crystals via both the stimulation and 102 augmentation approach.

\section{RESULTS}

104 Influence of the native ureolytic microbial community on the kinetics of calcium 105 carbonate precipitation

106 To investigate the influence of native ureolytic microbial community (NUMC) on calcium 107 carbonate precipitation at varying concentrations $(0,0.1,0.2,0.4,0.8,1.6$, and $3.2 \mathrm{OD})$, soluble 108 calcium concentration in the cementation medium was monitored for up to 288 hours (at an 109 interval of 12 hours). From fig. 1a it can be observed that the soluble calcium concentration 110 decreased over time in all the groups with varying rates except group A to which no NUMC 111 was added. The calcium concentration decreased to $50 \%$ from the initial value for group B at

$11296^{\text {th }}$ hour, for group C at $60^{\text {th }}$ hour, for group D at $48^{\text {th }}$ hour, for group E at $36^{\text {th }}$ hour, and group

$113 \mathrm{~F}$ and $\mathrm{G}$ at the $24^{\text {th }}$ hour. At the end of the process, the soluble calcium ions in all the sets were

114 exhausted, except in set A.

115 Kinetic constants $\left(\mathrm{K}_{\mathrm{cal}}\right)$ of $\mathrm{CaCO}_{3}$ precipitation were used to further investigate the effect of

116 various parameters on carbonate precipitation ${ }^{36}$. The monitored profiles were computationally

117 fitted using equation (4) to calculate $K_{\text {cal }}$ values (Fig 1a). Table 1 shows $K_{\text {cal }}$ values at varying

118 NUMC. The Kcal values of the fitted graphs increased from group A $\left(0 \mathrm{~h}^{-1}\right)$ to group G $(0.078$

$119 \mathrm{~h}^{-1}$ ). Further, it was found that the $\mathrm{K}_{\mathrm{cal}}$ values can be described by a Michelis-Menten (MM)

120 type equation (3) where $\mathrm{K}_{\mathrm{x}}$ is a constant value, $\mathrm{X}$ is the bacterial concentration, and $\mathrm{K}_{\mathrm{cal} \text {, } \max }$ is

121 the maximum kinetic constant for calcium carbonate precipitation. When $\mathrm{K}_{\mathrm{x}}$ is equal to $\mathrm{X}$, the 


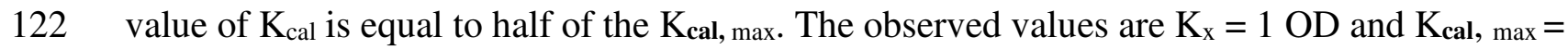

$1230.1 \mathrm{~h}^{-1}$ in this study. Fig. $1 \mathrm{~b}$ shows MM type plot that relates $\mathrm{K}_{\mathrm{cal}}$ and NUMC concentration.

$124 \quad K_{c a l}=\frac{K_{c a l, \max } X}{K_{x}+X}$

125 Fig. 1c shows the $\mathrm{pH}$ change over time in all the sets. In the cementation medium, $\mathrm{pH}$ was

126 observed to be between 6.5 and 8.3 in all the groups throughout the process. It can be seen that

127 the rate of $\mathrm{pH}$ change within the groups followed a similar trend except for the control group

128 A.

(a)

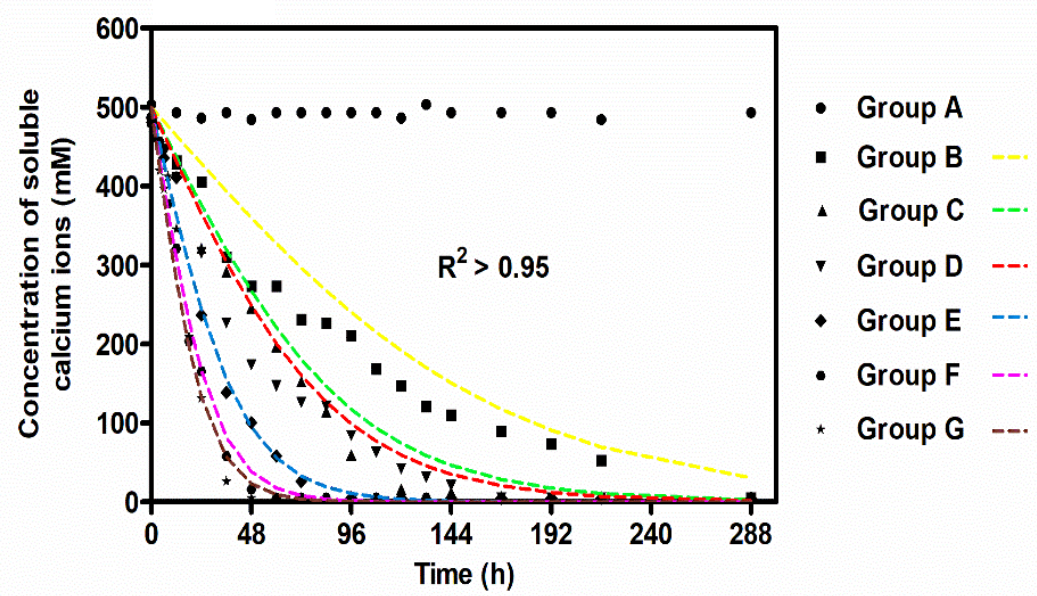

(b)

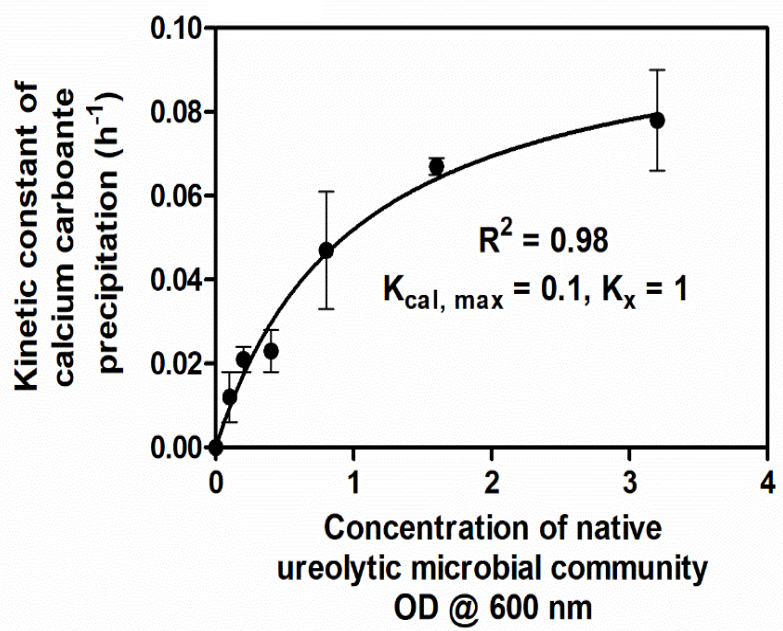

(c)

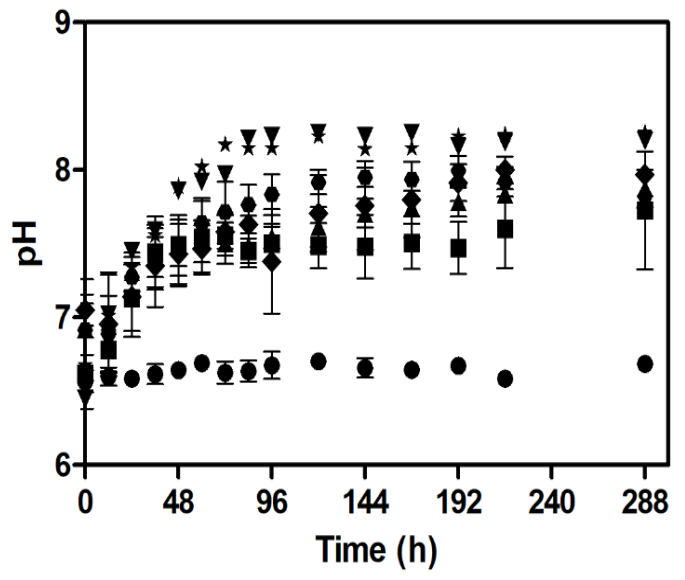

129 Figure 1. Concentration of soluble calcium ions over time (a). The relationship between

130 the kinetic constant of $\mathrm{CaCO}_{3}$ precipitation and concentration of the native ureolytic

131 microbial community (b). The variation of $\mathbf{p H}$ with time (c). Group A - 0 OD NUMC,

132 Group B - 0.1 OD NUMC, Group C - 0.2 OD NUMC, Group D - 0.4 OD NUMC, Group E -

1330.8 OD NUMC, Group F - 1.6 OD NUMC, and Group G - 3.2 OD NUMC. NUMC - Native 
134 Ureolytic Microbial Community. The coloured hidden lines are computationally fitted curves.

135 Error bars in the figure indicate the standard deviation of three independent trials.

\begin{tabular}{|c|c|c|c|c|}
\hline S. No & $\begin{array}{c}\text { Native } \\
\text { ureolytic } \\
\text { microbial } \\
\text { community } \\
\text { Group ID }\end{array}$ & $\begin{array}{c}\text { Concentration of } \\
\text { NUMC } \\
\text { OD @ } 600 \mathrm{~nm}\end{array}$ & $\begin{array}{c}\text { Kinetic constant } \\
\text { Of calcium } \\
\text { carbonate } \\
\text { precipitation } \\
\left(\mathrm{h}^{-1}\right)\end{array}$ & $\mathrm{R}^{2}$ \\
\hline 1 & Group A & 0 & 0 & NA \\
\hline 2 & Group B & 0.1 & $0.012 \pm 0.006$ & 0.97 \\
\hline 3 & Group C & 0.2 & $0.021 \pm 0.003$ & 0.98 \\
\hline 4 & Group D & 0.4 & $0.023 \pm 0.005$ & 0.98 \\
\hline 5 & Group E & 0.8 & $0.047 \pm 0.014$ & 0.99 \\
\hline 6 & Group F & 1.6 & $0.067 \pm 0.002$ & 0.99 \\
\hline 7 & Group G & 3.2 & $0.078 \pm 0.012$ & 0.98 \\
\hline
\end{tabular}

136 Table 1. The kinetic constant values of $\mathrm{CaCO}_{3}$ precipitation at varying native ureolytic 137 microbial community concentration. NUMC - Native Ureolytic Microbial Community. NA

138 - Not Applicable. \pm indicates the standard deviation of two independent trials.

\section{Influence of the native ureolytic microbial community on augmented $S$. pasteurii}

140 To investigate the influence of NUMC on $S$. pasteurii (bioaugmentation), soluble calcium

141 concentration in the cementation medium was monitored over time and fitted with equation

142 (4). Fig. 2a shows both observed and fitted curves from groups 1 to 7 . From this figure, an

143 exponential decrease of soluble calcium concentration was observed in all the groups with

144 immediate effect upon the addition of NUMC and S. pasteurii. The concentration was recorded

145 to be around zero at the $6^{\text {th }}$ hour. From the fitted curves, the values of the kinetic constants for

146 calcium carbonate precipitation were calculated (Table 2) and compared (Fig. 2b). From Table

1472 it can be seen that the kinetic constant values are $0.64,0.65,0.64,0.73,0.67,0.66,0.70$, and

$1480.78 \mathrm{~h}^{-1}$ for the groups 1 to 7 , respectively, i.e., the values were distributed between 0.64 and 
$1490.78 \mathrm{~h}^{-1}$. The change in the $\mathrm{pH}$ values of the cementation medium was also monitored (Fig. 2c)

150 and the observed values were found to be between 6.5 and 8 for all the groups.

(a)
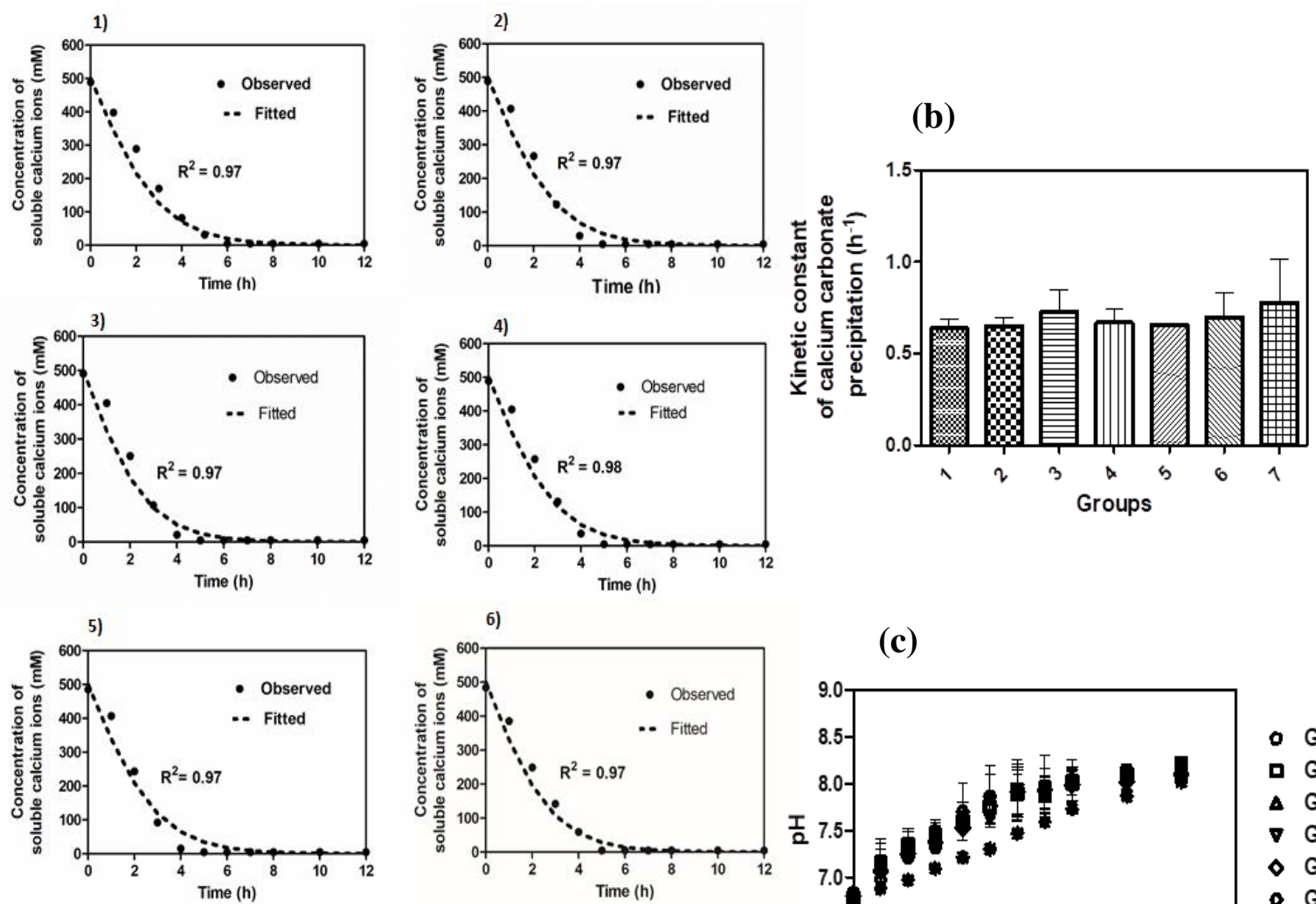

(c)
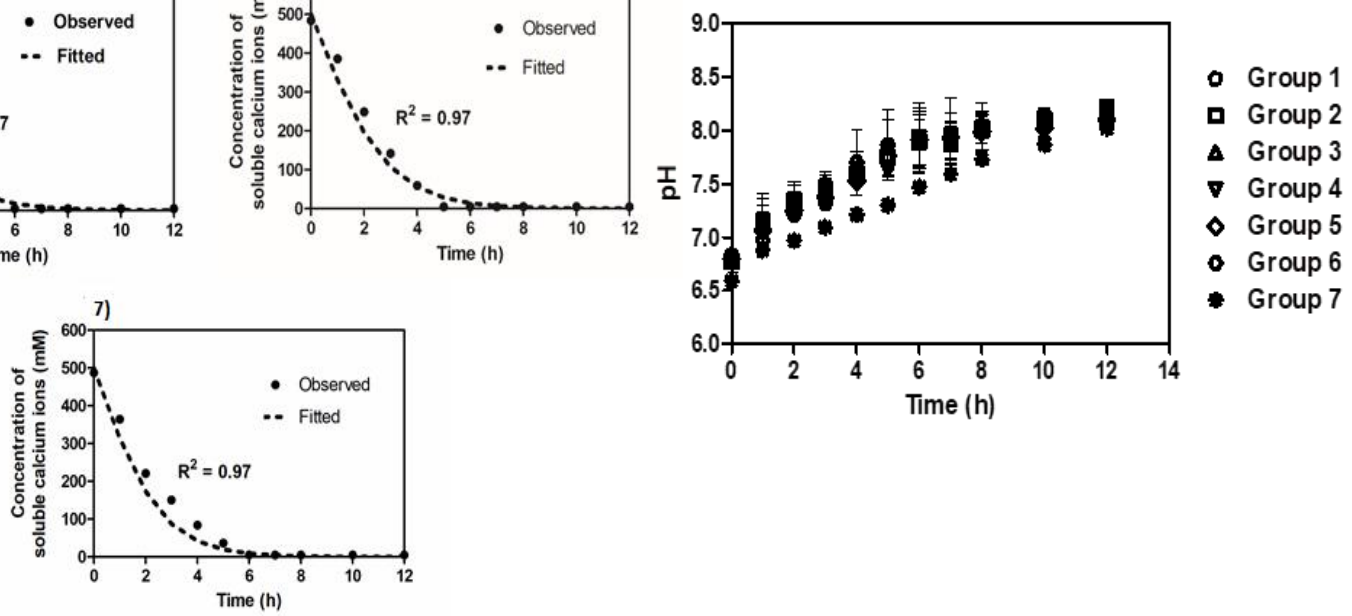

151 Figure 2. Concentration of soluble calcium ions over time - Bioaugmentation (a), comparison of the kinetic constant of $\mathrm{CaCO}_{3}$ precipitation - Bioaugmentation (b), the variation of $\mathbf{p H}$ with time (c). Group 1 - 0 OD NUMC + 0.4 OD S. pasteurii, Group 2 - 0.1 OD NUMC + 0.4 OD S. pasteurii, Group 3 - 0.2 OD NUMC + 0.4 OD S. pasteurii, 4) Group $4-0.4$ OD NUMC + 0.4 OD $S$. pasteurii, 0.8 OD NUMC + 0.4 OD $S$. pasteurii, 1.6 OD NUMC +0.4 OD S. pasteurii, and 3.2 OD NUMC + 0.4 OD S. pasteurii. NUMC - Native Ureolytic Microbial Community. Bioaugmentation - (NUMC + S. pasteurii). Error bars in the figure $2 \mathrm{~b}$ and $2 \mathrm{c}$ indicate the standard deviation of two independent trials.

\begin{tabular}{|c|c|c|c|c|c|}
\hline S. No & Group ID & $\begin{array}{l}\text { Concentration of } \\
\text { NUMC } \\
\text { OD @ 600 nm }\end{array}$ & $\begin{array}{c}\text { Concentration } \\
\text { of S. pasteurii } \\
\text { OD@ 600 nm }\end{array}$ & $\begin{array}{c}\text { Kinetic constant of } \\
\mathrm{CaCO}_{3} \\
\text { precipitation }\left(\mathrm{h}^{-1}\right)\end{array}$ & $\mathrm{R}^{2}$ \\
\hline 1 & Group 1 & 0 & & $0.64 \pm 0.05$ & 0.97 \\
\hline 2 & Group 2 & 0.1 & & $0.65 \pm 0.05$ & 0.97 \\
\hline
\end{tabular}




\begin{tabular}{|l|l|l|l|l|l|}
\hline 3 & Group 3 & 0.2 & \multirow{4}{*}{0.4} & $0.73 \pm 0.12$ & 0.97 \\
\hline 4 & Group 4 & 0.4 & $0.67 \pm 0.07$ & 0.98 \\
\hline 5 & Group 5 & 0.8 & & $0.66 \pm 0.00$ & 0.97 \\
\hline 6 & Group 6 & 1.6 & & $0.70 \pm 0.13$ & 0.97 \\
\hline 7 & Group 7 & 3.2 & & $0.78 \pm 0.24$ & 0.97 \\
\hline
\end{tabular}

159 Table 2. The kinetic constants of calcium carbonate precipitation. \pm indicates the standard 160 deviation of two independent trials. NUMC - Native Ureolytic Microbial Community. $S$. 161 pasteurii-Sporosarcina pasteurii.

162 Morphology and Phase of $\mathrm{CaCO}_{3}$

$163 \mathrm{CaCO}_{3}$ crystal morphology varies depending on the surface properties of the bacterial cell wall

164 composition especially extracellular polymeric substances and the solution chemistry of the

165 medium $^{26}$. Hence, the shape and size of precipitated crystals were analysed via scanning

166 electron micrography (Fig. 3). For groups 1 to 4, rhombohedral-shaped crystals of size $5-10$

$167 \mu \mathrm{m}$ were observed for the samples collected at the $12^{\text {th }}$ hour. For group 5 , the size of the

168 individual and clustered rhombohedral-shaped crystals was found to be $15-25 \mu \mathrm{m}$ for the

169 samples collected at the $12^{\text {th }}$ hour. For groups 6 and 7 , for the samples collected at the $12^{\text {th }}$ hour

170 the size of both the clustered rhombohedral-shaped crystals was $30-40 \mu \mathrm{m}$. SEM images

171 showed a cluster of rhombohedral-shaped crystals for the samples collected at $288^{\text {th }}$ hour for

172 the groups B to G. The size of these crystals varied between $35-100 \mu \mathrm{m}$. The polymorph is

173 a determining factor of strength and hardness of $\mathrm{CaCO}_{3}$ in $\mathrm{MICP}$. Therefore, the qualitative

174 and quantitative information of the $\mathrm{CaCO}_{3}$ crystals were obtained using the powdered XRD

175 technique (for the groups B to $\mathrm{G}$ at $288^{\text {th }}$ hour and the groups 1 to 7 at the $12^{\text {th }}$ hour). Fig. 4

176 shows the XRD spectrum of group B and the representative spectrums of all the other groups.

177 Tables 3 and 4 show the morphology and phase analysis of native ureolytic microbial

178 community and bioaugmentation studies. It was observed that only group B showed $2.3 \%$ of

179 the vaterite phase of $\mathrm{CaCO}_{3}$ crystals and all observed crystal phases of all the groups were of

180 the calcite phase. 

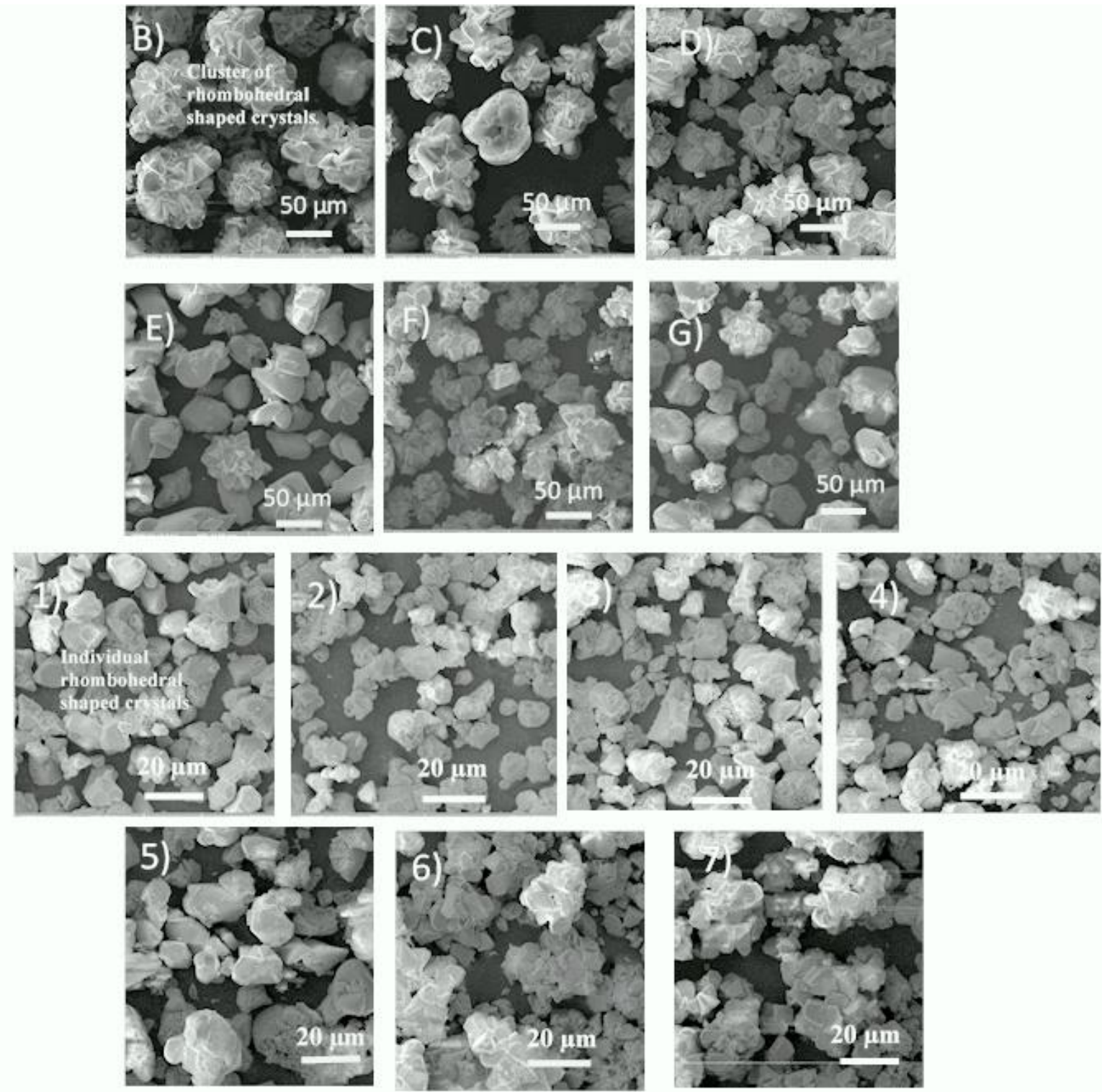

182 Figure 3. Scanning electron microscopy images of $\mathrm{CaCO}_{3}$ crystals. Groups $\mathrm{B}$ to $\mathrm{G}$ 183 (NUMC) and 1 to 7 (Bioaugmentation). B) - 0.1 OD NUMC, C) - 0.2 OD NUMC, D) - 0.4 184 OD NUMC, E) - 0.8 OD NUMC, F) - 1.6 OD NUMC, and G) - 3.2 OD. 1) - 0 OD NUMC + 185 0.4 OD $S$. pasteurii, 2) - 0.1 OD NUMC + 0.4 OD $S$. pasteurii, 3) - 0.2 OD NUMC + 0.4 OD 186 S. pasteurii, 4) Group 4 - 0.4 OD NUMC + 0.4 OD $S$. pasteurii, 5) 0.8 OD NUMC + 0.4 OD 187 S. pasteurii, 6) 1.6 OD NUMC + 0.4 OD $S$. pasteurii, and 7) 3.2 OD NUMC + 0.4 OD $S$. 188 pasteurii. NUMC - Native Ureolytic Microbial Community and Bioaugmentation - (NUMC $189+$ S. pasteurii).

\begin{tabular}{|c|c|c|c|c|c|c|}
\hline S. & No & Group ID & $\begin{array}{c}\text { Concentration of } \\
\text { NUMC } \\
\text { OD @ 600 } \mathrm{nm}\end{array}$ & $\begin{array}{c}\text { The average size of } \\
\text { the crystal } \\
(\mu \mathrm{m})\end{array}$ & Shape & \multicolumn{2}{|c|}{ Phase } \\
\cline { 5 - 7 } & Group A & 0 & NA & NA & NA & NA \\
\hline 2 & Group B & 0.1 & $80-100$ & $\begin{array}{c}\text { Cluster of } \\
\text { rhombohedral }\end{array}$ & 2.3 & 97.7 \\
\hline 3 & Group C & 0.2 & $70-90$ & $\begin{array}{c}\text { Cluster of } \\
\text { rhombohedral }\end{array}$ & 0 & 100 \\
\hline 4 & Group D & 0.4 & $60-80$ & $\begin{array}{c}\text { Cluster of } \\
\text { rhombohedral }\end{array}$ & 0 & 100 \\
\hline
\end{tabular}




\begin{tabular}{|c|c|c|c|c|c|c|}
\hline 5 & Group E & 0.8 & $55-65$ & $\begin{array}{c}\text { Individual and } \\
\text { Cluster of } \\
\text { rhombohedral }\end{array}$ & 0 & 100 \\
\hline 6 & Group F & 1.6 & $40-60$ & $\begin{array}{c}\text { Individual and } \\
\text { Cluster of } \\
\text { rhombohedral }\end{array}$ & 0 & 100 \\
\hline 7 & Group G & 3.2 & $35-55$ & $\begin{array}{c}\text { Individual and } \\
\text { Cluster of } \\
\text { rhombohedral }\end{array}$ & 0 & 100 \\
\hline
\end{tabular}

190 Table 3. The influence of native ureolytic microbial community concentration on the morphology and phase of $\mathrm{CaCO}_{3}$ crystals. NUMC - Native Ureolytic Microbial Community.

NA - Not Applicable.

\begin{tabular}{|c|c|c|c|c|c|c|}
\hline $\begin{array}{l}\text { S. } \\
\text { No }\end{array}$ & Group ID & $\begin{array}{l}\text { Concentration } \\
\text { of NUMC } \\
\text { OD @ } 600 \mathrm{~nm}\end{array}$ & $\begin{array}{l}\text { Concentration of } \\
\text { S. pasteurii } \\
\text { OD@ } 600 \mathrm{~nm}\end{array}$ & $\begin{array}{l}\text { The average size of } \\
\text { the crystal } \\
(\mu \mathrm{m})\end{array}$ & Shape & Phase \\
\hline 1 & Group 1 & 0 & \multirow{7}{*}{ 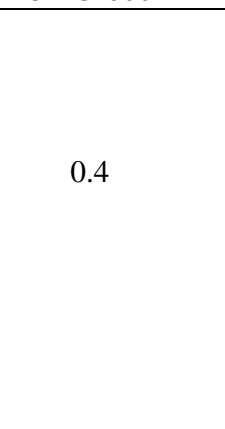 } & $5-10$ & Rhombohedral & \multirow{7}{*}{ Calcite } \\
\hline 2 & Group 2 & 0.1 & & $5-10$ & Rhombohedral & \\
\hline 3 & Group 3 & 0.2 & & $5-10$ & Rhombohedral & \\
\hline 4 & Group 4 & 0.4 & & $5-10$ & Rhombohedral & \\
\hline 5 & Group 5 & 0.8 & & $15-25$ & $\begin{array}{l}\text { Individual and cluster } \\
\text { of rhombohedral }\end{array}$ & \\
\hline 6 & Group 6 & 1.6 & & $30-40$ & $\begin{array}{c}\text { Cluster of } \\
\text { rhombohedral }\end{array}$ & \\
\hline 7 & Group 7 & 3.2 & & $30-40$ & $\begin{array}{c}\text { Cluster of } \\
\text { rhombohedral }\end{array}$ & \\
\hline
\end{tabular}

193 Table 4. The morphology and phase characterization of $\mathrm{CaCO}_{3}$ crystals -

194 Bioaugmentation. NUMC - Native Ureolytic Microbial Community.

a)

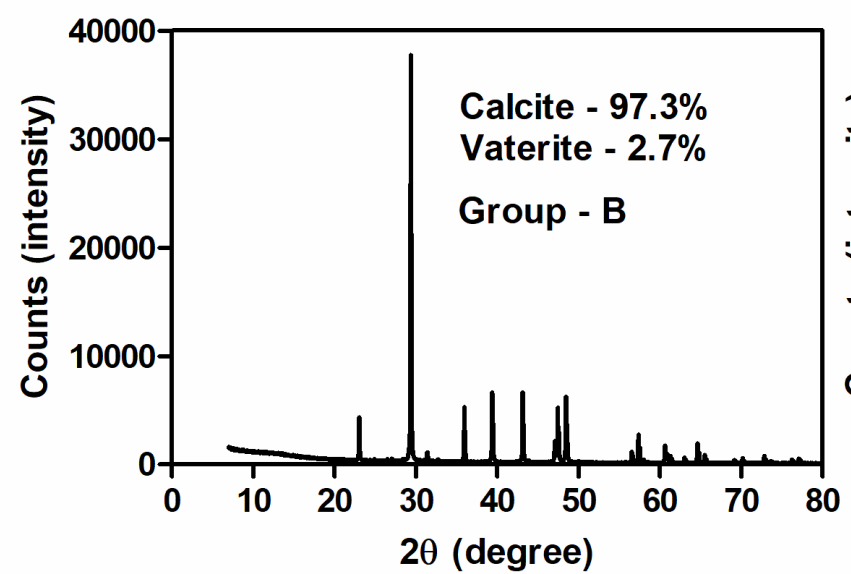

b)

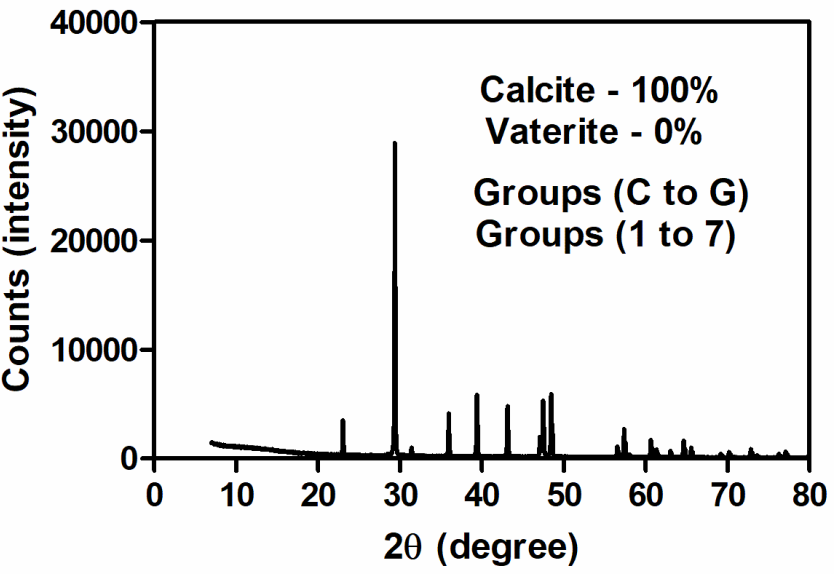

195 Figure 4. XRD spectrum of $\mathrm{CaCO}_{3}$ polymorphs. a) Group B (NUMC) and b) Groups C 196 to G (NUMC) and 1 to 7 (bioaugmentation). Group B - 0.1 OD NUMC, Group C - 0.2 OD 197 NUMC, Group D - 0.4 OD NUMC, Group E - 0.8 OD NUMC, Group F - 1.6 OD NUMC, 198 and Group G - 3.2 OD NUMC. Group 1 - 0 OD NUMC + 0.4 OD S. pasteurii, Group 2 - 0.1 199 OD NUMC + 0.4 OD S. pasteurii, Group $3-0.2$ OD NUMC + 0.4 OD $S$. pasteurii, 4) Group $2004-0.4$ OD NUMC + 0.4 OD $S$. pasteurii, 0.8 OD NUMC + 0.4 OD $S$. pasteurii, 1.6 OD NUMC $201+0.4$ OD S. pasteurii, and 3.2 OD NUMC + 0.4 OD S. pasteurii. NUMC - Native Ureolytic 202 Microbial Community, Bioaugmentation - (NUMC + S. pasteurii $)$. 


\section{DISCUSSION}

204 This study investigated the effect of NUMC on the augmented S. pasteurii by comparing the 205 biocementing potentials of NUMC and augmented S. pasteurii in the presence of NUMC. To 206 understand the effect, the kinetics of $\mathrm{CaCO}_{3}$ precipitation, change in $\mathrm{pH}$, the morphology of 207 the $\mathrm{CaCO}_{3}$ crystals formed and the phase of the precipitated crystals were analysed. The soluble 208 calcium concentration was measured, and its kinetics was analysed using a logistic equation

209 (4) to compare the biocementation potentials of NUMC and augmented S. pasteurii in the 210 presence of NUMC. $\mathrm{pH}$ was also monitored to identify the range that favours $\mathrm{CaCO}_{3}$ 211 precipitation. SEM and XRD analyses were performed, which revealed the morphology (size 212 and shape) and mineralogy of the crystals formed.

213 NUMC is capable of inducing $\mathrm{CaCO}_{3}$ precipitation in their microenvironment ${ }^{39}$. In fig. 1a, the 214 soluble calcium concentration decreased in all the groups. It could be due to carbonate ions 215 generated in the MICP process during urea hydrolysis, which facilitates precipitation of soluble 216 calcium around the bacterial cell wall in a cementation medium ${ }^{2}$. The complete exhaustion in

217 the soluble calcium ions in the groups (group $B-G$ ) indicates that all the calcium in the 218 medium is converted into $\mathrm{CaCO}_{3}$. Moreover, the supplied equimolar concentration of urea is 219 enough for the complete conversion of $\mathrm{CaCO}_{3}$. The observed decrease in $\mathrm{CaCO}_{3}$ precipitation 220 rate (Fig. 1a) is due to encapsulation of $\mathrm{CaCO}_{3}$ on the bacterial surface that limits the transport 221 of nutrients transport including urea across the bacterial membrane ${ }^{40}$. The rate of soluble 222 calcium depletion was observed to increase on increasing the NUMC concentration in the cementation medium. Increasing the NUMC concentration increases the total urease activity

224 of the system, which in turn increases the soluble calcium depletion rate ${ }^{22}$. Moreover, the results show a positive correlation between $\mathrm{CaCO}_{3}$ precipitation rate and the cell concentration ${ }^{22-24}$. Furthermore, the relationship between $\mathrm{K}_{\mathrm{cal}}$ and NUMC concentration could be used to design and develop a similar process for field applications. The kinetic constant $\mathrm{K}_{\mathrm{cal}}$, Max in the 
mathematical equation 3 denotes the maximum ability of the NUMC to achieve MICP at a faster rate, in this case, $0.1 \mathrm{~h}^{-1}$. The kinetic constant $\mathrm{K}_{\mathrm{x}}$ is equal to $1 \mathrm{OD}$, which indicates the concentration of NUMC required to achieve half the value of $\mathrm{K}_{\mathrm{cal} \text {, Max. }}$.

S. pasteurii is a widely employed bacterial strain for bioaugmentation of soil consolidation and stabilization process because of its high urease-producing potential ${ }^{41}$. Hence, this bacterium was chosen as the model organism for this study. Supersaturation Index (SI) is one of the key parameters for the initiation of $\mathrm{CaCO}_{3}$ precipitation ${ }^{32}$. Quick $\mathrm{CaCO}_{3}$ precipitation was observed for groups 1-7 in the cementation medium. This indicates that the cementation medium has reached the required SI in a short time. $\mathrm{pH}$ also affects the SI, which is evident from the reported result $^{42}$ (Fig. 2c). Moreover, the ready availability of the positively charged calcium ions in the vicinity of the negatively charged bacterial surface could also favour quick $\mathrm{CaCO}_{3}$ precipitation $^{3}$.

240 The observed $\mathrm{K}_{\mathrm{cal}}$ value of group $1\left(0.64 \mathrm{~h}^{-1}\right)$ with $S$. pasteurii of 0.4 OD was 6-fold higher

241 than the $\mathrm{K}_{\mathrm{cal}, \mathrm{Max}}\left(0.1 \mathrm{~h}^{-1}\right)$ value of NUMC. This indicates that $S$. pasteurii has relatively high

$242 \mathrm{CaCO}_{3}$ precipitation potential compared to NUMC. However, the observed results are in

243 contrast to the reported studies that suggest biostimulation is the best possible approach for

244 biocementation ${ }^{39,43}$. This could be due to the presence of different NUMC and varying study conditions between different research groups. The influence of varying concentrations of NUMC on the bioaugmentation potential of S. pasteurii was also investigated. However, no

247 significant changes in the $\mathrm{K}_{\mathrm{cal}}$ values were observed within the groups when $\mathrm{K}_{\mathrm{cal}}$ values were 248 compared between groups 1 to 7 (Fig. 2b). This indicates that the presence of NUMC did not 249 influence the $\mathrm{CaCO}_{3}$ precipitation potential of $S$. pasteurii even at a concentration as high as 2508 -fold (group 7) over a period of two weeks in this study.

251 The $\mathrm{pH}$ of the cementation medium greatly influences the $\mathrm{CaCO}_{3}$ precipitation and also affects 252 bacterial urease production ${ }^{42}$. In this study, the $\mathrm{pH}$ of the cementation medium of all the groups 
irrespective of the group type varied between 6.5 to 8.3 . This indicates that the $\mathrm{CaCO}_{3}$ precipitation occurred between the observed $\mathrm{pH}$ range. Urease activity of the bacteria results in the generation of ammonium ions that in turn affects the $\mathrm{pH}$ of the cementation medium. The rate of $\mathrm{pH}$ change was observed to be comparatively high for groups 1 to 7 , which could be attributed to the high urease activity of $S$. pasteurii ${ }^{44}$. However, the same was not observed in groups A to G which could be attributed to the low urease activity of NUMC.

The molecular mechanism of $\mathrm{CaCO}_{3}$ crystal nucleation, growth, and morphology (size and shape) in the biocementation process is a complex phenomenon. Nature of the bacterial community, solution chemistry of the cementation medium (supersaturation index), the concentration of nutrients, calcium, and $\mathrm{Mg}^{2+}$ ions significantly influence the crystal growth kinetics and characteristics ${ }^{45,46,48}$. In this study, groups B to G with only NUMC at different concentrations showed a cluster of rhombohedral-shaped crystals, sized $35-100 \mu \mathrm{m}$ at $288^{\text {th }}$ hour. Whereas groups 1 to 4 with $S$. pasteurii in particular, yielded individual crystals of size $5-10 \mu \mathrm{m}$ at $12^{\text {th }}$ hour. A decrease in crystal size during bioaugmentation is due to the high driving force, which results in the fast attaining of the saturation state during $\mathrm{CaCO}_{3}$ precipitation. According to the classical nucleation theory: the nucleus size of the crystal decreases when the driving force to reach the saturation state for the precipitation increases ${ }^{47}$. This result is consistent with a previous study by Cuthbert and co-workers who reported that a

271 higher initial saturation state influences the lower-sized crystals ${ }^{40}$.

272 The generation of ammonium ions and inorganic carbon due to the effective urea hydrolysis 273 increases the $\mathrm{pH}$ and alkalinity of the cementation medium. It develops the oversaturated 274 cementation solution that leads to the spontaneous $\mathrm{CaCO}_{3}$ precipitation ${ }^{32}$. It is possible to 275 obtain different phases of $\mathrm{CaCO}_{3}$ including aragonite, calcite, vaterite, and two hydrated 276 crystalline phases as monohydric calcite and ikaite in the MICP process ${ }^{1}$. This is because the 277 polymorphism of $\mathrm{CaCO}_{3}$ is highly dependent on various parameters of the precipitation 
environment. In general, many studies reported that the phase transition from metastable vaterite phase to more stable calcite phase during the $\mathrm{CaCO}_{3}$ precipitation process ${ }^{22,26}$. But, the specific phase preference by different bacterial cultures could depend on several parameters including the type of bacteria, specific amino acid sequences of urease, organic acid production, extracellular polymeric substances of the bacteria, the kinetics of the precipitation process, cementation medium composition, and other physicochemical parameters that affect supersaturation index of the solution ${ }^{48-52}$.

In this study, no visible $\mathrm{CaCO}_{3}$ crystals were observed in group A due to a lack of bacterial metabolic activity that leads to the undersaturation of the system. In the case of group B, besides $97.7 \%$ of calcite, $2.3 \%$ of vaterite form of $\mathrm{CaCO}_{3}$ crystals were formed at the end $288^{\text {th }}$ hour.

On the other hand, in all other groups including group $C$ to $G$ and group 1 to 7 only calcite form of $\mathrm{CaCO}_{3}$ crystals was observed at the end of precipitation. From the results, it is evident that calcite is the predominant polymorph of $\mathrm{CaCO}_{3}$ crystals in both cases. It is also evident that the presence of NUMC does not affect calcite formation. Moreover, the observed results follow the Ostwald rule of crystallization, which states that thermodynamically crystal

293 formation favors the less soluble calcite than more soluble vaterite ${ }^{27}$. There could be a possible delay in the transformation of vaterite to calcite form when the rate of $\mathrm{CaCO}_{3}$ precipitation is slow. Hence, this could be attributed to the slow transformation of vaterite to calcite in groups B to $G^{27}$. Nevertheless, only rhombohedral-shaped calcite form of crystals was observed in all

297 the groups despite different bacteria employed in this study at the end of the process. These 298 calcite form crystals have superior engineering properties (strength and stiffness) compared to vaterite and aragonite forms of $\mathrm{CaCO}_{3}$ crystals.

\section{Conclusions}

301 In this study, we investigated the influence of native ureolytic microbial communities (NUMC) 
pasteurii. We evaluated the biogenic $\mathrm{CaCO}_{3}$ precipitation kinetics of NUMC at varying concentrations in the presence and absence of S. pasteurii along with its impact on the morphomineralogical characteristics of the precipitated carbonates. Our key findings were that the concentration of cells has a major impact on the reaction kinetics as well as morpho-

307 mineralogical properties of precipitated carbonate crystals as we recorded in the case of NUMC

308 as well as $S$. pasteurii. The rate of ureolysis and calcium carbonate precipitation in the case of

309 NUMC is very slow compared to S. pasteurii; and this can have a major impact on its

310 application. S. pasteurii is highly efficient in biocementation even in the presence of native

311 ureolytic cultures at different concentrations. Ureolytic and calcium carbonate precipitation

312 kinetics of $S$. pasteurii were not found to be impacted significantly in the presence of NUMC;

313 even when their concentration is eight folds higher. Although the rate of ureolysis and 314 carbonate precipitation is low in the case of NUMC, but it has a positive impact on the quality

315 of crystals. The size of calcite crystals in the case of NUMC with low metabolic activity is 316 much higher (6-10 times) compared to smaller crystals formed by $S$. pasteurii. This

317 demonstrates that depending upon the nature of application and time frame for cementation in

318 field-scale/ other areas, it is crucial to have the fundamental information on biocementation 319 potential of native communities and then look for alternatives as supplementation of $S$. pasteurii. Taken together, the results from the current study demonstrate, for the first time, that

321 the quantitative and qualitative properties of biocement can be tailored utilising the information

322 of ureolytic and carbonate precipitation kinetics with native as well as augmented cultures. This

323 finding can enable several new possibilities for ureolysis driven biocementation in the area of 324 advanced functional living materials. 


\section{MATERIALS AND METHODS}

\section{Bacteria, Growth medium, and OD measurement}

327 The bacteria used in this study are the Native Ureolytic Microbial Community (NUMC) ${ }^{53}$ and 328 S. pasteurii (ATCC 11859). The bacteria were grown in Ammonium -Yeast extract medium 329 (ATCC 1376) contains yeast extract (20 g/L), ammonium sulphate (10 g/L), and $0.13 \mathrm{M}$ tris 330 base $\left(\mathrm{pH}\right.$ 9) were maintained at $30^{\circ} \mathrm{C}$ and $180 \mathrm{rpm}$. The individual components of the growth 331 medium were autoclaved and mixed after cooling under sterile conditions. To measure the 332 concentration of the overnight grown NUMC and S. pasteurii, the media containing bacteria 333 were centrifuged at $4500 \mathrm{rpm}$ for 10 minutes and the optical density was measured using a 334 spectrophotometer (Thermo scientific, Genesis 10S) at $600 \mathrm{~nm}$ with $0.85 \%$ sodium chloride 335 solution as blank.

\section{Cementation medium and conditions}

337 The cementation medium provides required nutrients and cementation components for NUMC and S. pasteurii. $100 \mathrm{~mL}$ of cementation medium was prepared by mixing $65 \mathrm{~mL}$ of autoclaved distilled water containing $0.2 \mathrm{~g}$ of yeast extract followed by the addition of required

340 concentrations of NUMC and $S$. pasteurii cell pellet obtained after centrifugation (4500 rpm

341 for 10 minutes). Then 10 and $25 \mathrm{~mL}$ of filter-sterilized $5 \mathrm{M}$ urea and $2 \mathrm{M}$ calcium chloride 342 dihydrate solution were added, respectively. The cementation medium containing a bacterial 343 pellet was maintained at $30^{\circ} \mathrm{C}$ and $180 \mathrm{rpm}$ in a shaker incubator.

\section{Enumeration of bacterial concentration}

345 The bacterial concentration was measured by the serial dilution method. Petri plates containing

$3461.5 \%$ agar in ATCC 1376 media were used to spread the bacteria; 1 OD of bacteria in saline 347 was found to contain cells equivalent to $4.5^{*} 10^{8}$ cells $/ \mathrm{mL}$. 
349 This study was designed to investigate the influence of NUMC on the biocementation potential

350 of augmented $S$. pasteurii. The study was divided into two major groups. Each group is further 351 subdivided into seven subgroups namely A to G and 1 to 7 . The groups A, B, C, D, E, F, and

352 G have overnight grown NUMC pellet mixed with cementation medium at concentrations of $3530,0.1,0.2,0.4,0.8,1.6$, and $3.2 \mathrm{OD}$, respectively. The groups $1,2,3,4,5,6$, and 7 contain 354 fixed concentration of $S$. pasteurii (0.4 OD) and NUMC at concentrations of 0, 0.1, 0.2, 0.4, $3550.8,1.6$, and $3.2 \mathrm{OD}$, respectively in the cementation medium. To monitor the process, $2 \mathrm{~mL}$ 356 of samples were taken and centrifuged at $3000 \mathrm{rpm}$ for 10 minutes at regular intervals of time.

357 The obtained supernatant was used to measure soluble calcium concentration and $\mathrm{pH}$ until the 358 process was complete.

\section{Measurement of soluble calcium ions and $\mathbf{p H}$}

360 The soluble calcium ions were measured by using the complexometric titration procedure ${ }^{54} .40$

$361 \mu \mathrm{L}$ of the sample was diluted to $10 \mathrm{~mL}$ followed by the addition of $400 \mu \mathrm{L} 1 \mathrm{~N}$ sodium 362 hydroxide solution and a few drops of hydroxy naphthol blue disodium salt (1\% W/V) solution 363 indicators. Then the mixture was titrated against $1 \mathrm{mM}$ EDTA disodium salt solution until the 364 colour change from pink to blue was observed. The slope of the standard $\left(0-2.5 \mathrm{mM} \mathrm{CaCl}_{2}\right)$ 365 was used to calculate the actual concentration of calcium ions in the sample. The change in $\mathrm{pH}$ during biocementation was recorded using a pH meter (Thermo scientific, Orion star, A211).

Morphology and phase analysis of $\mathrm{CaCO}_{3}$

368 The $\mathrm{CaCO}_{3}$ precipitate from the cementation medium was analysed at the end of the process.

$36930 \mathrm{~mL}$ of sample was taken was centrifuged at $4500 \mathrm{rpm}$ for 10 minutes. The pellets obtained 370 were washed twice with distilled water and dried at $37^{\circ} \mathrm{C}$ overnight. Then the dried crystals were subjected to scanning electron microscopy and XRD. 


\section{Morphology (Size and Shape)}

373 The variable pressure electron microscope (VP - SEM, Zeiss, EVO 40 -XVP, 2008) was used

374 to observe the size and shape of the $\mathrm{CaCO}_{3}$ precipitate. The samples were placed on carbon-

375 aluminum tape and coated using a carbon evaporative coater (creissington, 2080C, 2011). The

376 beam intensity and voltage were 8.0 and $10 \mathrm{kV}$, respectively with a working distance of around

$37715 \mathrm{~mm}$. The secondary electron imaging was used to obtain scanning electron micrographs.

378 The sizes of the crystals from the micrographs were obtained using IMAJEJ (1.8.0 172)

379 software.

$380 \quad$ Phase

381 Bruker D8 advance diffractometer with Ni-filtered $\mathrm{Cu} \mathrm{K \alpha}$ radiation (40 kV, $40 \mathrm{~mA})$ over the

382 range $7-120^{\circ} 2 \theta$, with a step size of $0.015^{\circ}$ was used to collect the XRD data. The powdered

$383 \mathrm{CaCO}_{3}$ was resuspended in ethanol and deposited onto low-background holders. Further, the

384 phase identification was done in Bruker EVA 5.2 using the Crystallography Open Database

385 (COD) (http://www.crystallogrphy.net/). The phase quantification was done in Topas

386 Academic 7 using the Rietveld method. Also, the crystal structures were identified from the

387 COD.

388 Calculation of kinetic constants for calcium carbonate precipitation

389 In this study, the soluble calcium concentration over time was fitted with equation 4 using the

390 solver function in Excel (2016 MSO) to calculate kinetic constants of $\mathrm{CaCO}_{3}$ precipitation.

$391 \quad C_{c a l}(\mathrm{t})=\mathbf{2} C_{\mathbf{0}} /\left(\mathbf{1}+\mathrm{e}^{K_{c a l} t}\right)$

392 Where, $\mathrm{C}_{\mathrm{o}}=$ initial concentration of calcium $(\mathrm{mM})$,

$393 \mathrm{C}_{\mathrm{cal}}(\mathrm{t})=$ soluble calcium concentration $(\mathrm{mM})$ at given time,

$394 \mathrm{t}=$ time $(\mathrm{h})$ and,

$395 \mathrm{~K}_{\mathrm{cal}}=$ kinetic constant of calcium carbonate precipitation $\left(\mathrm{h}^{-1}\right)$. 


\section{References}

1. Dhami, N. K., Reddy, M. S. \& Mukherjee, M. S. Biomineralization of calcium carbonates and their engineered applications: A review. Front. Microbiol. 4, 1-14 (2013).

2. Stocks-Fischer, S., Galinat, J. K. \& Bang, S. S. Microbiological precipitation of CaCO 3. Soil Biol. Biochem. 31, 1563-1571 (1999).

401

3. Dejong, J. T., Mortensen, B. M., Martinez, B. C. \& Nelson, D. C. Bio-mediated soil improvement. Ecol. Eng. 36, 197-210 (2010).

4. Ferris, F. G., Phoenix, V., Fujita, Y. \& Smith, R. W. Kinetics of calcite precipitation induced by ureolytic bacteria at 10 to $20^{\circ} \mathrm{C}$ in artificial groundwater. Geochim. Cosmochim. Acta 68, 1701-1710 (2004).

5. Fujita, Y., Grant Ferris, F., Daniel Lawson, R., Colwell, F. S. \& Smith, R. W. Calcium carbonate precipitation by ureolytic subsurface bacteria. Geomicrobiol. J. 17, 305-318 (2000)

6. Kumari, D., Qian, X. Y., Pan, X., Achal, V. \& Li, Q. Microbially-induced Carbonate Precipitation for Immobilization of Toxic Metals. Adv. Appl. Microbiol. 94, 79-108 (2016). 7. Wu, J., Wang, X. B., Wang, H. F. \& Zeng, R. J. Microbially induced calcium carbonate precipitation driven by ureolysis to enhance oil recovery. RSC Adv. 7, 37382-37391 (2017). micro-organisms. ACI Mater. J. 98, 3-9 (2001).

9. Van Tittelboom, K., De Belie, N., De Muynck, W. \& Verstraete, W. Use of bacteria to repair cracks in concrete. Cem. Concr. Res. 40, 157-166 (2010). 10. Mitchell, A. C., Dideriksen, K., Spangler, L. H., Cunningham, A. B. \& Gerlach, R. Microbially enhanced carbon capture and storage by mineral-trapping and solubilitytrapping. Environ. Sci. Technol. 44, 5270-5276 (2010).

11. Phillips, A. J. et al. Engineered applications of ureolytic biomineralization: A review. 
Biofouling 29, 715-733 (2013).

12. Van Paassen, L. A., Ghose, R., van der Linden, T. J. M., van der Star, W. R. L. \& van Scale Biogrout Experiment. J. Geotech. Geoenvironmental Eng. 136, 1721-1728 (2010). 13. Whiffin, V. S., van Paassen, L. A. \& Harkes, M. P. Microbial Carbonate Precipitation as a Soil Improvement Technique. Geomicrobiol. J. 24, 417-423 (2007).

14. Zhang, J. L. et al. Screening of bacteria for self-healing of concrete cracks and optimization of the microbial calcium precipitation process. Appl. Microbiol. Biotechnol. 100, 6661-6670 (2016).

15. Mortensen, B. M., Haber, M. J., DeJong, J. T., Caslake, L. F. \& Nelson, D. C. Effects of environmental factors on microbial induced calcium carbonate precipitation. J. Appl. Microbiol. 111, 338-349 (2011).

16. Martinez, B. C. et al. Experimental Optimization of Microbial-Induced Carbonate Precipitation for Soil Improvement. J. Geotech. Geoenvironmental Eng. 139, 587-598 (2013).

17. Soon, N.W., Lee, L.M., Khun, T.C. \& Ling, H.S. Factors Affecting Improvement in Engineering Properties of Residual Soil through Microbial-Induced Calcite Precipitation. Artic. J. Geotech. Geoenvironmental Eng. 140, 04014006 (2014).

18. Zhao, Q. et al. Factors Affecting Improvement of Engineering Properties of MICPTreated Soil Catalyzed by Bacteria and Urease. J. Mater. Civ. Eng. 26, 04014094 (2014). 19. Oral, Ç. M. \& Ercan, B. Influence of $\mathrm{pH}$ on morphology, size and polymorph of room temperature synthesized calcium carbonate particles. Powder Technol. 339, 781-788 (2018).

20. Li, M., Wen, K., Li, Y. \& Zhu, L. Impact of Oxygen Availability on Microbially Induced Calcite Precipitation (MICP) Treatment. Geomicrobiol. J. 35, 15-22 (2018). 
21. Peng, J. \& Liu, Z. Influence of temperature on microbially induced calcium carbonate precipitation for soil treatment. PLoS One 14, e0218396 (2019).

22. Wen, K., Li, Y., Amini, F. \& Li, L. Impact of bacteria and urease concentration on precipitation kinetics and crystal morphology of calcium carbonate. Acta Geotech. 15, 1727 (2020).

23. Okwadha, G. D. O. \& Li, J. Optimum conditions for microbial carbonate precipitation. Chemosphere 81, 1143-1148 (2010).

24. Lauchnor, E. G., Topp, D. M., Parker, A. E. \& Gerlach, R. Whole cell kinetics of ureolysis by Sporosarcina pasteurii. J. Appl. Microbiol. 118, 1321-1332 (2015).

25. Mitchell, A. C. et al. Kinetics of calcite precipitation by ureolytic bacteria under aerobic and anaerobic conditions. Biogeosciences 16, 2147-2161 (2019).

26. Heveran, C. M. et al. Engineered Ureolytic Microorganisms Can Tailor the Morphology and Nanomechanical Properties of Microbial-Precipitated Calcium Carbonate. Sci. Rep. 9, 1-13 (2019).

27. Mitchell, A. C. \& Grant Ferris, F. The influence of bacillus pasteurii on the nucleation and growth of calcium carbonate. Geomicrobiol. J. 23, 213-226 (2006). ureolytic microbial calcium carbonate precipitation. Appl. Environ. Microbiol. 69, 49014909 (2003).

29. Rodriguez-Navarro, C., Jimenez-Lopez, C., Rodriguez-Navarro, A., Gonzalez-Muñoz,

M. T. \& Rodriguez-Gallego, M. Bacterially mediated mineralization of vaterite. Geochim. Cosmochim. Acta 71, 1197-1213 (2007).

30. Chen, L. et al. Bacteria-mediated synthesis of metal carbonate minerals with unusual morphologies and structures. Cryst. Growth Des. 9, 743-754 (2009).

31. Dhami, N. K., Mukherjee, A. \& Reddy, M. S. Micrographical, mineralogical and nano- 
mechanical characterisation of microbial carbonates from urease and carbonic anhydrase producing bacteria. 94, 443-454 (2016). (2000).

33. Burbank, M. B., Weaver, T. J., Green, T. L., Williams, B. \& Crawford, R. L. Precipitation of calcite by indigenous microorganisms to strengthen liquefiable soils. Geomicrobiol. J. 28, 301-312 (2011).

34. Gomez, M. G. et al. Field-scale bio-cementation tests to improve sands. Proc. Inst. Civ. Eng. Gr. Improv. 168, 206-216 (2015).

35. Gomez, M. G. et al. Large-Scale Comparison of Bioaugmentation and Biostimulation Approaches for Biocementation of Sands. J. Geotech. Geoenvironmental Eng. 143, 04016124 (2017).

36. Tobler, D. J. et al. Comparison of rates of ureolysis between Sporosarcina pasteurii and an indigenous groundwater community under conditions required to precipitate large volumes of calcite. Geochim. Cosmochim. Acta 75, 3290-3301 (2011).

37. Gomez, M. G., Graddy, C. M. R., Dejong, J. T. \& Nelson, D. C. Biogeochemical Changes During Bio-cementation Mediated by Stimulated and Augmented Ureolytic Microorganisms. Sci. Rep. 1-15 (2019).

38. Dhami, N. K., Alsubhi, W. R., Watkin, E. \& Mukherjee, A. Bacterial community dynamics and biocement formation during stimulation and augmentation: Implications for soil consolidation. Front. Microbiol. 8, 1267 (2017). calcite precipitation. Appl. Sci. 10, 2905 (2020). 
precipitated by S. Pasteurii biofilms and limits due to bacterial encapsulation. Ecol. Eng. 41, 32-40 (2012).

41. Gomez, M. G., DeJong, J. T., Anderson, C. M., Nelson, D. C. \& Graddy, C. M. Large-

Scale Bio-Cementation Improvement of Sands. in Geotechnical and Structural Engineering Congress 2016 - Proceedings of the Joint Geotechnical and Structural Engineering Congress 2016 941-949 (American Society of Civil Engineers, 2016).

42. Hammes, F. \& Verstraete, W. Key roles of pH and calcium metabolism in microbial carbonate precipitation. Rev. Environ. Sci. Biotechnol. (2002).

43. Gomez, M. G., Graddy, C. M. R., DeJong, J. T., Nelson, D. C. \& Tsesarsky, M. Stimulation of Native Microorganisms for Biocementation in Samples Recovered from Field-Scale Treatment Depths. J. Geotech. Geoenvironmental Eng. 144, 04017098 (2018). 44. Bachmeier, K. L., Williams, A. E., Warmington, J. R. \& Bang, S. S. Urease activity in microbiologically-induced calcite precipitation. J. Biotechnol. 93, 171-181 (2002). Sporosarcina pasteurii using response surface methodology. Ecol. Eng. 62, 168-174 (2014).

46. Chekroun, K. Ben et al. Precipitation and growth morphology of calcium carbonate induced by Myxococcus xanthus: Implications for recognition of bacterial carbonates. $J$. Sediment. Res. 74, 868-876 (2004).

47. Oxtoby, D. W. Homogeneous nucleation: Theory and experiment. J. Phys. Condens. Matter 4, 7627-7650 (1992). 48. Al Imran, M., Shinmura, M., Nakashima, K. \& Kawasaki, S. Effects of Various Factors on Carbonate Particle Growth Using Ureolytic Bacteria. Mater. Trans. 59, 1520-1527 (2018). 
concrete. Appl. Microbiol. Biotechnol. 102, 3059-3070 (2018).

50. Sondi, I. \& Salopek-Sondi, B. Influence of the primary structure of enzymes on the formation of $\mathrm{CaCO}_{3}$ polymorphs: A comparison of plant (Canavalia ensiformis) and bacterial (Bacillus pasteurii) ureases. Langmuir 21, 8876-8882 (2005).

51. Rodriguez-Blanco, J. D., Shaw, S. \& Benning, L. G. The kinetics and mechanisms of amorphous calcium carbonate (ACC) crystallization to calcite, via vaterite. Nanoscale $\mathbf{3}$, 265-271 (2011).

52. Rodriguez-Navarro, C., Jroundi, F., Schiro, M., Ruiz-Agudo, E. \& González-Muñoz,

M. T. Influence of substrate mineralogy on bacterial mineralization of calcium carbonate: Implications for stone conservation. Appl. Environ. Microbiol. 78, 4017-4029 (2012). 53.Dubey, A. et al. Biocementation mediated by stimulated ureolytic microbes from brahmaputra riverbank for mitigation of soil erosion. 26 February 2021, preprint (version 1) available at research square [https://doi.org/10.21203/rs.3.rs-235959/v1]. 54. APHA/AWWA/WEF. Standard Methods for the Examination of Water and Wastewater. Stand. Methods 541 (2012).

\section{Acknowledgments}

537 The authors would like to acknowledge the Microscopy and Microanalysis Facility, Curtin 538 University, Western Australia for SEM and XRD analysis. The current study was funded by 539 the Australian Research Council Linkage Project LP180100132.

\section{Authors Contributions}

541 R.M. performed the experiments; R.M., N.K.D., G.K.S., and A.M. contributed to experimental

542 design and data analysis; R.M., and N.K.D. wrote the manuscript. All the authors reviewed the 543 manuscript.

\section{Additional Information}

545 Competing financial interests: The authors declare no competing financial interests. 